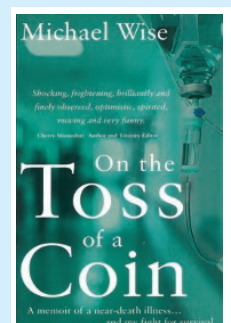

\section{ON THE TOSS OF A COIN}

Michael Wise

Matador, 2017

price $\mathrm{f} 9.99 \mathrm{pp} 368$

ISBN 9781785899218

The author Michael Wise is a well-respected specialist in oral surgery and restorative dentistry. He is working as a visiting professor at University College London, alongside running his own successful practice. He is a fit and active individual with a love for learning and treating patients holistically.

This all changes over a matter of days. Michael's wife rings for an ambulance after he becomes very unwell whilst taking a bath. After a substantial stay in an intensive treatment unit, he survives but his life has been altered in unimaginable ways due to his brush with death.

It would have been easy to become demoralised or even depressed following such a life-altering event. For Michael Wise, he saw it as an opportunity to reflect upon the service he received from both private and NHS healthcare, aiming to improve the experience and outcome for those unlucky enough to follow in his footsteps. His reflections also cover difficult topics such as consent, assisted dying, behaviour and body language of clinicians, and patient misconceptions on their diagnosis, to name a few.

He is meticulous in his detailing throughout the book and gives many references to statistics, facts and quotes. These are coupled with very honest and human anecdotes of his own life which give the book a sense of humour. Yes, even Michael Wise has experienced sick through his fingers whilst taking an impression!

In my opinion the best part is the fantastic appendices crammed with information about acute kidney injury (AKI), the history of dialysis, and a checklist of coping strategies which Michael uses but which could well be used for any difficult time.

This book made me think. How would I react? Would I lose hope? Would I fight to live? Who would support me? He makes you feel as if you are alongside him as he has captured this event though his personal dialogue and precise detail. There are even entries from those closest to him, covering their innermost thoughts, feelings, and emotions through this difficult time.

In short, this is the story of the pulling together of a family, the fight of a man for his life, a selfless act of an individual, and the reality of a long and difficult rehabilitation. A true reminder to never take what we have for granted.

C. Porter

\title{
Associate working environments: call for volunteers
}

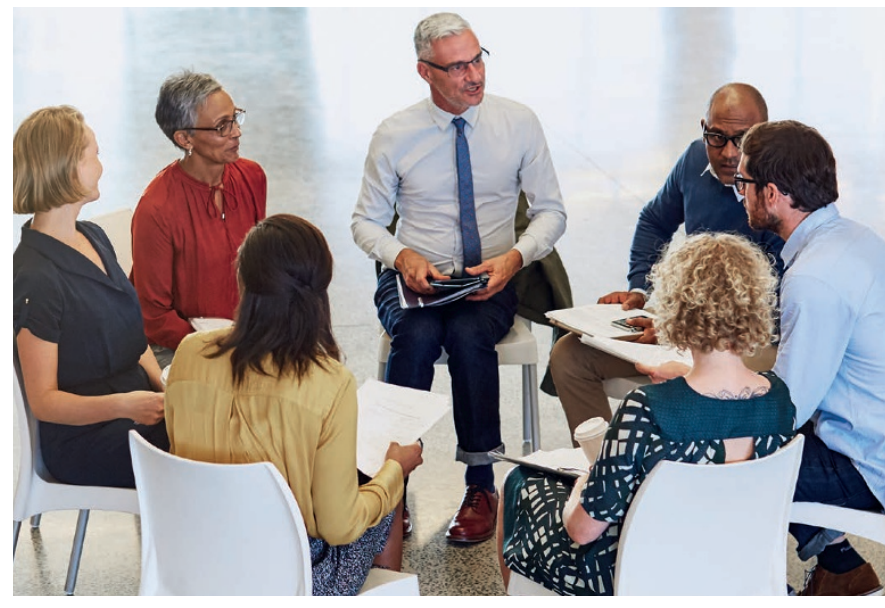

The British Dental Association (BDA) is exploring the effect of different working environments on associates in general practice to inform policy and drive future strategy.

As part of this the BDA is looking for associates to take part in focus groups and interviews to share their experiences.

Both focus groups and interviews will be facilitated by the BDA Research Team and last approximately one hour.

If you are a current UK dentist and would like to support the BDA's work in this area by taking part in a focus group or interview, you can find out more at www.bda.org/dentalenvironment and express your interest by emailing ellena.o'selmo@bda.org before 30 October 2017. 